\title{
Slotting Allowances and Scarce Shelf Space*
}

\author{
Leslie M. Marx ${ }^{\dagger}$ \\ Duke University
}

\author{
Greg Shaffer \\ University of Rochester
}

September 2008

\begin{abstract}
Slotting allowances are upfront payments that manufacturers make to retailers to obtain shelf space. They have become widespread in recent years, particularly in the grocery industry, and have been a policy issue in antitrust for some time. A popular view is that these payments arise because retailers have more products from which to choose than can be profitably carried given the availability of shelf space. According to this view, slotting allowances are caused by the scarcity of shelf space. In this paper, we show that the causality can also go the other way: the scarcity of shelf space may in part be due to the emergence of slotting allowances. This has policy implications. Because fewer products can be carried when shelf space is scarce, it follows that slotting allowances may be anticompetitive even when they have no effect on retail prices.
\end{abstract}

JEL Classification Codes: D43, L13, L14, L42

${ }^{*}$ We thank Yaron Yehezkel and seminar participants at Duke University, Texas A\&M, Washington University in St. Louis, and the Fourth Annual International Industrial Organization Conference in Boston for helpful comments. ${ }^{\dagger}$ Fuqua School of Business, Duke University, Durham, NC 27708; email: marx@duke.edu.

${ }^{\ddagger}$ Simon School of Business, University of Rochester, Rochester, NY 14627; email: shaffer@simon.rochester.edu. 


\section{Introduction}

The typical supermarket has room for less than 30,000 products, and yet, at any given time, there are over 100,000 products from which to choose. ${ }^{1}$ Retailers distinguish between those products that are likely to fail in their local area and those that are likely to succeed, but even in the best of circumstances, they are often left with many more viable products than can be carried profitably. When this happens, a retailer needs some mechanism (formal or informal) to help in the selection process. One practice that has become widespread in recent years is the practice of putting one's shelf space up for bid and letting the manufacturers compete for the retailer's patronage. The manufacturers who offer the best deals to the retailer obtain the shelf space. Typically, the deals include potentially large, upfront payments that are independent of the retailer's subsequent quantity purchases. These upfront payments are referred to in the trade press as slotting allowances.

Slotting allowances have received a lot of attention in antitrust, ${ }^{2}$ and there is a growing academic literature that seeks to identify their competitive effects. A branch of this literature considers the effects of slotting allowances on the retailer's choices of which products to carry. One concern is that large, dominant firms will buy up scarce shelf space in order to exclude their smaller rivals from the market. ${ }^{3}$ According to this view, large firms will win the shelf-space bidding wars not necessarily because they make better products, but because they are willing to pay more to protect their monopoly rents than small firms are willing to pay to be competitive (Shaffer, 2005). In a related view, the large firm may have easier access to capital markets or face lower interest rates, giving it a tangible advantage over smaller rivals. In either case, it is argued that products that may be more socially beneficial are being excluded. The opposing view is that slotting allowances can be thought of as the market price of a scarce asset (shelf space) that, according to traditional price theory, has optimal allocative properties (Sullivan, 1997). According to this view, the firms that offer retailers the best deals will be the ones whose products generate the largest private and social benefit, and thus only the manufacturers of the best products will obtain shelf space.

\footnotetext{
${ }^{1}$ According to the Food Marketing Institute, the typical supermarket carries approximately 15,000 products. A typical superstore (defined as a supermarket with at least 40,000 square feet of total selling area) carries approximately 25,000 products. See http://www.fmi.org/factsfigs/?fuseaction = superfact.

${ }^{2}$ See "Slotting: Fair for Small Business and Consumers? Hearing Before the Senate Committee on Small Business," 106th Congress, 1st Session 386 (1999), and the two recent reports by the Federal Trade Commission, "Report on the Federal Trade Commission's Workshop on Slotting Allowances and Other Marketing Practices in the Grocery Industry," (2001), and "Slotting Allowances in the Retail Grocery Industry: Selected Case Studies in Five Product Categories," (2003).

${ }^{3}$ In addition to the FTC reports mentioned in footnote 2, see also the Canadian Competition Bureau's report on slotting allowances, "The Abuse of Dominance Provisions as Applied to the Retail Grocery Industry," available at http://cb-bc.gc.ca/epic/internet/incb-bc.nsf/vwGeneratedInterE/ct02317e.html\#5.2.
} 
Both viewpoints take as given the scarcity of shelf space and imply that slotting allowances arise in response to this scarcity. By contrast, in this paper, we show that the scarcity of shelf space itself may depend on the availability of slotting allowances in the sense that the retailer is more likely to limit its shelf space in an environment with slotting allowances than without. This reverses the typically assumed direction of causality. Although this finding represents a significant departure from conventional thinking on slotting allowances, the idea we wish to explore is straightforward and comes from the theory of rent-shifting. ${ }^{4}$ The choice of how much shelf space to build can be viewed as a strategic decision by the retailer. By limiting its shelf space, a retailer can force manufacturers to compete more vigorously for its patronage, which then allows it to extract from them better terms of trade. ${ }^{5}$ Slotting allowances can help in the transfer of surplus because they allow the surplus to be transferred more efficiently. In contrast, when slotting allowances are prohibited, a retailer's ability to shift rents is less effective and the main drawback of a shortage of shelf space - a smaller overall joint profit due to the reduced number of products carried-becomes more salient.

Our model has implications for antitrust policy. In the conventional way of thinking, the concern is whether a dominant firm can plausibly induce a smaller rival to exit by buying up scarce shelf space. Reasoning that the dominant firm will not buy up extra shelf space unless it can be assured that its rival's product is the one being excluded and not some unrelated product, the focus of antitrust scrutiny has been on the ancillary provisions that sometimes accompany contracts with slotting allowances. For example, a contract in which a manufacturer promises to pay a retailer a lump-sum amount with no mention of its rivals' products is looked upon more favorably than a contract in which a manufacturer offers a retailer a lump-sum payment in exchange for contingencies on the retailer's sales of rival products. ${ }^{6}$ In our model, a prohibition of ancillary provisions in contracts that mention rivals would be ineffective, and it would not address the fundamental problem. This is because the source of the problem is the scarcity of the shelf space itself and not how the shelf space is allocated among the various products. By limiting its shelf space, the retailer links all products, whether or not they are otherwise independent in demand.

\footnotetext{
${ }^{4}$ The use of contracts to shift rents among vertically related firms was first studied by Aghion and Bolton (1987). See also the papers by Innes and Sexton (1994), Spier and Whinston (1995), and Marx and Shaffer (2004).

${ }^{5}$ The result that the retailer might be able to increase its profit by excluding manufacturers can be found in O'Brien and Shaffer (1997). See also the papers by Dana (2004) and Inderst and Shaffer (2007). The mechanism at work here, however, is fundamentally different. In these other models, the contracting takes place simultaneously. In our model, contracting occurs sequentially, which allows for the possibility of rent shifting.

${ }^{6}$ To give an example, consider a contract in which a manufacturer offers to pay the retailer some amount of money upfront if the retailer agrees to purchase a certain minimum percentage of its requirements from the manufacturer, say, for example, $80 \%$. Such a contract features both a slotting allowance and a market-share discount. In its 2001 report on slotting allowances, the Federal Trade Commission expressed concern that such contracts might lead to inefficient exclusion and that consumer prices would be higher because of the concomitant decrease in competition.
} 
Thus, irrespective of whether there are ancillary provisions in a particular manufacturer's contract that identify which firms are or are not competitors, some products will necessarily be excluded. Under this view, the retailer is to blame and the exclusion is best seen as being retailer induced.

Although slotting allowances are anticompetitive in our model, they do not affect consumer prices, and they do not lead to inefficiencies in the product-selection process. ${ }^{7}$ Prices are not affected because a manufacturer obtains its shelf space at the expense of an unrelated product, leaving market conditions unchanged, and the product-selection process is not distorted because, conditional on the available shelf space, the retailer will carry the same products whether or not slotting allowances are feasible. Instead, slotting allowances are anticompetitive because they contribute to a shortage of shelf space, leading to a reduction in the variety of products sold to consumers.

Other explanations of slotting allowances either tend to be specific to new products, or are unrelated to whether shelf space is scarce. ${ }^{8}$ For example, in the case of new products, one explanation is that slotting allowances serve as a screening device to enable a downstream firm to distinguish high quality products from low quality products, and another explanation is that slotting allowances allow for the efficient sharing of the risk of new product failure. The literature in this vein includes Kelly (1991), Chu (1992), Sullivan (1997), Lariviere and Padmanabhan (1997), and Bloom, et al. (2000). Slotting allowances have also been posited to arise for strategic reasons when retailers have all the bargaining power vis-a-vis their upstream suppliers. ${ }^{9}$ Shaffer (1991) and Foros and Kind (2008) suggest that retailers will use their bargaining power to obtain slotting allowances rather than wholesale price concessions in order to avoid dissipating their gains when competing against other downstream firms; and in a model with one upstream firm and competing downstream firms that can make take-it-or-leave-it offers, Marx and Shaffer (2007) show that slotting allowances arise in equilibrium whenever there is asymmetry downstream (either on the demand or cost side) and lead to exclusion in the sense that the manufacturer does not obtain distribution at all retail outlets.

In contrast, our model applies to any product, new or established, that requires shelf space, and we find that slotting allowances arise only when manufacturers have bargaining power. We posit that slotting allowances go hand-in-hand with the scarcity of shelf space; they are not observed if

\footnotetext{
${ }^{7}$ This contrasts with the view that slotting allowances may lower consumer prices because they are an efficient mechanism for the retailer to equate the supply and demand of shelf space (cf. Sullivan, 1997), and the view that slotting allowances may raise consumer prices because in their absence retailers would use their bargaining powers to negotiate lower wholesale prices, which would then be passed through to the benefit of consumers (cf. Shaffer, 1991).

${ }^{8}$ There is little empirical literature on the subject, mostly because of the lack of data, and what literature there is tends to focus on new products (see Gundlach and Bloom, 1998; Rao and Mahi, 2003; and Israilevich, 2004).

${ }^{9}$ For a non-strategic explanation of slotting allowances that is not specific to new products, see Kuksov and Pazgal (2007), who find that slotting allowances can efficiently compensate retailers for their fixed costs of distribution.
} 
shelf space is plentiful, but they are observed if shelf space is scarce. However, instead of concluding that slotting allowances arise because of the scarcity of shelf space, we show that slotting allowances may actually be contributing to the scarcity of shelf space. The extent to which they contribute depends on the retailer's bargaining power. We find there is an inverse relationship between a retailer's bargaining power and slotting allowances. Conditional on having market power, the more bargaining power a retailer has, the less likely it is to limit its shelf space as a means of extracting rent. Slotting allowances do not arise, for example, if the retailer can make take-it-or-leave-it offers. This may explain why some retailers such as Wal-Mart do not avail themselves of these payments.

The rest of the paper proceeds as follows. We introduce the model and notation in Section 2. In Section 3, we solve for the equilibrium payoffs of each firm for the benchmark case in which slotting allowances are prohibited. We then show in Section 4 that the retailer may have an incentive to limit its shelf space in order to obtain better terms of trade, and that slotting allowances weakly increase these incentives. We discuss the model's policy implications and conclude in Section 5.

\section{Model}

The simplest model in which to capture the interaction between slotting allowances and scarce shelf space is one in which there are two manufacturers, $X$ and $Y$, and a single retailer (or, alternatively, multiple retailers, with each one having local monopoly power over consumers in its area). Consumers choose what and how much to buy given the set of products and prices offered to them.

Costs for the two manufacturers are given by $c_{X}(x)$ and $c_{Y}(y)$, respectively, where $x$ is the quantity purchased from manufacturer $X$ and $y$ is the quantity purchased from manufacturer $Y$. We assume that $c_{i}(\cdot)$ is increasing, continuous, and unbounded, with $c_{i}(0)$ for all $i=X, Y$.

On the demand side, we assume the manufacturers' products are independent, so that an increase in the retail price of one does not affect consumer demand for the other. This assumption is made for simplicity and to capture the notion that a retailer's shelf-space decisions are typically storewide (i.e., shelf space allocated to one product in a particular location may come at the expense of unrelated products in other parts of the store). Alternatively, one can imagine cases in which a retailer's shelf-space decisions are necessarily localized, (i.e., which products to put in the freezer section), so that the retailer may have to choose between products that are imperfect substitutes. However, it is straightforward to show that our results are robust to this extension of the model.

The game has four stages. In stage one, the retailer decides how much shelf space to build, 
and slotting allowances, if any, are offered by the manufacturers. We conceptualize the retailer's shelf space as consisting of slots of fixed width and assume, for simplicity, that the retailer can build at most two slots. Thus, in stage one, the retailer can build zero, one, or two slots of shelf space. Adequate display and promotion of a product requires exactly one slot of shelf space. If a manufacturer obtains a slot, it can satisfy any amount of consumer demand for its product. In contrast, if a manufacturer does not obtain a slot, it is effectively excluded from distribution. We say that shelf space is plentiful if the retailer builds two slots and scarce otherwise. Given these assumptions, the retailer can adequately display and sell both products if and only if shelf space is plentiful. By contrast, the retailer can display and sell at most one product if shelf space is scarce.

After observing whether the retailer's shelf space is plentiful or scarce, each manufacturer can bid to purchase (or rent) any available slot by offering slotting allowances. ${ }^{10}$ If the retailer accepts a manufacturer's offer for a given slot, then it receives the promised lump-sum payment and control over that slot reverts to the manufacturer whose slotting allowance was accepted. If the retailer rejects a manufacturer's offer for a given slot, then no payment is made and control over that slot remains in the retailer's hands. The retailer can accept only as many offers as it has slots available.

Contract negotiations take place in stages two and three. In stage two, the retailer and manufacturer $X$ negotiate contract $T_{X}$ for the purchase of manufacturer $X$ 's product. In stage three, the retailer and manufacturer $Y$ negotiate contract $T_{Y}$ for the purchase of manufacturer $Y$ 's product. ${ }^{11}$ We place no restrictions on the form of the contracts other than to assume that each contract specifies the retailer's payment solely as a function of how much the retailer buys of that manufacturer's product, e.g., $T_{X}: \mathbb{R}_{+} \rightarrow \mathbb{R} \cup\{\infty\}$, and similarly for $T_{Y}$. Thus, we do not allow contracts to depend on both manufacturers' quantities. ${ }^{12}$ This restriction, which is critical for our results, can be justified if the retailers' purchases are not easily observable or verifiable across manufacturers, or if such contracts would invite unwelcome scrutiny from antitrust authorities (see the discussion in the introduction).

In stage four, the retailer makes its quantity choices and pays the manufacturers according to its contracts with them. In the absence of a contract, a manufacturer's continuation payoff is zero (i.e.,

\footnotetext{
${ }^{10}$ In practice, slotting allowances are typically offered in exchange for a fixed amount of shelf space and a prespecified length of time for which the firm's product must be displayed. We simplify here by assuming that slots are indivisible, and that the length of time for which the product must be on display is for the duration of the game.

${ }^{11}$ The assumption that the retailer contracts sequentially with the manufacturers as opposed to simultaneously turns out to be inconsequential if shelf space is plentiful. However, if shelf space is scarce, then contracting sequentially turns out to benefit manufacturer $X$ and the retailer, who gain from being able to shift rent from manufacturer $Y$.

${ }^{12}$ Without this restriction, the retailer and manufacturer $X$ could extract all of manufacturer $Y$ 's surplus through the use of penalty clauses (Aghion and Bolton, 1987). See also the results in Marx and Shaffer (2004), who focus on the efficiency properties and extent of surplus extraction when contracts can depend on both sellers' quantities.
} 
its payoff gross of any slotting allowance it may already have paid). Otherwise, manufacturer $X$ 's continuation payoff is $T_{X}(x)-c_{X}(x)$ and manufacturer $Y$ 's continuation payoff is $T_{Y}(y)-c_{Y}(y)$.

Let $R(x, y)$ denote the maximum revenue that can be earned if the retailer purchases from both manufacturers, and let $R_{X}(x) \equiv R(x, 0)$ and $R_{Y}(y) \equiv R(0, y)$ denote the retailer's revenue if it purchases from only manufacturer $X$ or $Y$, respectively. Then, plentiful shelf space implies that

$$
R(x, y)=R_{X}(x)+R_{Y}(y)
$$

By contrast, if shelf space is scarce, so that the retailer can only sell one product, then

$$
R(x, y)=\max \left\{R_{X}(x), R_{Y}(y)\right\}
$$

If the retailer has contracts in place with both manufacturers, then its payoff gross of any slotting allowances it may have received is $R(x, y)-T_{X}(x)-T_{Y}(y)$. If negotiations with only manufacturer $Y$ fail, the retailer's gross payoff is $R_{X}(x)-T_{X}(x)$. If negotiations with only manufacturer $X$ fail, the retailer's gross payoff is $R_{Y}(y)-T_{Y}(y)$. If negotiations with both manufacturers fail, then the retailer's gross payoff is zero. We assume that $R(\cdot, \cdot)$ is continuous and bounded, with $R(0,0)=0$.

In negotiations, we assume that the retailer and manufacturer $i$ choose $T_{i}$ to maximize their joint payoff, and that surplus is divided such that each player receives its disagreement payoff (which we define below) plus a share of the incremental gains from trade (the joint payoff of the retailer and manufacturer $i$ if they trade minus their joint payoff if they do not trade), with proportion $\lambda_{i} \in[0,1]$ going to manufacturer $i$. Our assumption of a fixed division of the incremental gains from trade admits several interpretations. For example, if manufacturer $i$ makes a take-it-or-leave-it offer to the retailer, then $\lambda_{i}=1$. If the retailer makes a take-it-or-leave-it offer to manufacturer $i$, then $\lambda_{i}=0$. Finally, if the retailer and manufacturer $i$ split the gains from trade equally, then $\lambda_{i}=\frac{1}{2}$.

We solve for the equilibrium strategies (we restrict attention to pure strategies and contracts for

which optimal quantity choices in stage four exist) of the retailer and manufacturers $X$ and $Y$ by working backwards, taking our assumptions about the outcome of each negotiation as given. The equilibrium we identify corresponds to the subgame-perfect equilibrium of the related four-stage game in which the assumed bargaining solution is embedded in the three players' payoff functions.

\section{Solving the model}

We begin by solving for the equilibrium payoffs of each firm when slotting allowances are prohibited. For this purpose, let $\Pi(x, y) \equiv R(x, y)-c_{X}(x)-c_{Y}(y)$ denote the overall joint payoff of the 
manufacturers and the retailer, and let $\Pi_{X Y} \equiv \max _{x, y \geq 0} \Pi(x, y)$ denote its maximized value. It is also useful to define $\Pi_{X} \equiv \max _{x \geq 0} \Pi(x, 0)$ and $\Pi_{Y} \equiv \max _{y \geq 0} \Pi(0, y)$. Note that if shelf space is plentiful then $\Pi_{X Y}=\Pi_{X}+\Pi_{Y}$. By contrast, if shelf space is scarce then $\Pi_{X Y}=\max \left\{\Pi_{X}, \Pi_{Y}\right\}$.

\section{Stage four — retailer's quantity choices}

Let $\left(x^{* *}\left(T_{X}, T_{Y}\right), y^{* *}\left(T_{X}, T_{Y}\right)\right)$ denote the retailer's profit-maximizing quantity choices if it has contract $T_{X}$ in place with manufacturer $X$ and contract $T_{Y}$ in place with manufacturer $Y$, i.e.,

$$
\left(x^{* *}\left(T_{X}, T_{Y}\right), y^{* *}\left(T_{X}, T_{Y}\right)\right) \in \arg \max _{x, y \geq 0} R(x, y)-T_{X}(x)-T_{Y}(y) .
$$

Note that if shelf space is plentiful, then the retailer's profit-maximizing choice of $x$ will depend on $T_{X}$ only, and analogously for the retailer's profit-maximizing choice of $y$. By contrast, if shelf space is scarce, the retailer's quantity choices will in general depend on both manufacturer's contracts.

If instead negotiations with manufacturer $Y$ have failed, and the retailer only has a contract in place with manufacturer $X$, then we denote the retailer's optimal quantity choice by $x^{*}\left(T_{X}\right)$, where

$$
x^{*}\left(T_{X}\right) \in \arg \max _{x \geq 0} R_{X}(x)-T_{X}(x) .
$$

Define $y^{*}\left(T_{Y}\right)$ analogously for the case in which negotiations with only manufacturer $X$ have failed.

The quantities $x^{* *}$ and $x^{*}$ (and analogously for $y^{* *}$ and $y^{*}$ ) are related given the simple structure of the model. If shelf space is plentiful, then $x^{* *}$ and $x^{*}$ are the same. If shelf space is scarce, then either $x^{* *}=x^{*}$ if the retailer sells manufacturer $X$ 's product, or $x^{* *}$ is chosen to minimize $T_{X}\left(x^{* *}\right)$.

\section{Stage three-negotiations with manufacturer $Y$}

In stage three, taking $T_{X}$ as given, manufacturer $Y$ and the retailer will choose $T_{Y}$ to solve

$$
\max _{T_{Y}} R\left(x^{* *}, y^{* *}\right)-T_{X}\left(x^{* *}\right)-c_{Y}\left(y^{* *}\right)
$$

such that manufacturer $Y$ receives its share of the incremental gains from trade

$$
\pi_{Y}=\lambda_{Y}\left(R\left(x^{* *}, y^{* *}\right)-T_{X}\left(x^{* *}\right)-c_{Y}\left(y^{* *}\right)-\left(R_{X}\left(x^{*}\right)-T_{X}\left(x^{*}\right)\right)\right)
$$

Since $T_{X}$ is fixed when $T_{Y}$ is chosen, it follows from (5) and (6) that $T_{Y}$ will be chosen such that ${ }^{13}$

$$
\left(x^{* *}\left(T_{X}, T_{Y}\right), y^{* *}\left(T_{X}, T_{Y}\right)\right) \in \arg \max _{x, y \geq 0} R(x, y)-T_{X}(x)-c_{Y}(y) .
$$

\footnotetext{
${ }^{13}$ Given $T_{X}$, there is no reason to distort the retailer and manufacturer $Y$ 's joint-profit-maximizing quantities.
} 
If there is no contract between the retailer and manufacturer $X$, then $T_{Y}$ will be chosen to maximize $\Pi\left(0, y^{*}\right)$ such that manufacturer $Y$ earns $\lambda_{Y} \Pi\left(0, y^{*}\right)$ and the retailer earns $\left(1-\lambda_{Y}\right) \Pi\left(0, y^{*}\right)$. Thus, manufacturer $Y$ 's payoff in this case will be $\lambda_{Y} \Pi_{Y}$ and the retailer's payoff will be $\left(1-\lambda_{Y}\right) \Pi_{Y}$.

\section{Stage two-negotiations with manufacturer $X$}

In stage two, manufacturer $X$ and the retailer will choose $T_{X}$ to solve

$$
\max _{T_{X}} \Pi\left(x^{* *}, y^{* *}\right)-\pi_{Y}
$$

subject to contract $T_{Y}$ 's inducing the retailer to choose $\left(x^{* *}, y^{* *}\right)$ such that

$$
\left(x^{* *}, y^{* *}\right) \in \arg \max _{x, y \geq 0} R(x, y)-T_{X}(x)-c_{Y}(y)
$$

and manufacturer $X$ receiving its share of the incremental gains from trade with the retailer

$$
\pi_{X}=\lambda_{X}\left(\Pi\left(x^{* *}, y^{* *}\right)-\pi_{Y}-\left(1-\lambda_{Y}\right) \Pi_{Y}\right)
$$

The program in (8) and (10) implies that $T_{X}$ will be chosen to maximize the difference between $\Pi\left(x^{* *}, y^{* *}\right)$ and manufacturer $Y$ 's profit, such that $\left(x^{* *}, y^{* *}\right)$ maximizes the retailer's joint payoff with manufacturer $Y$, and manufacturer $X$ earns its share of the gains from trade with the retailer. In solving it, note that $x^{*}, x^{* *}$, and $y^{* *}$ are functions of $T_{x}$ only, and that (9) implies that

$$
R\left(x^{* *}, y^{* *}\right)-T_{X}\left(x^{* *}\right)-c_{Y}\left(y^{* *}\right) \geq \max _{y \geq 0} R\left(x^{*}, y\right)-T_{X}\left(x^{*}\right)-c_{Y}(y) .
$$

In choosing their optimal contract, the retailer and manufacturer $X$ may be able to exploit their first-mover advantage by shifting rents from manufacturer $Y$. However, their ability to do so is constrained by the independence of the products, whether shelf space is scarce or plentiful, and by the inequality in (11). If manufacturer $Y$ 's surplus is fully extracted before (11) binds, then $\pi_{Y}=0$ and $T_{X}$ is chosen such that $\left(x^{* *}, y^{* *}\right) \in \arg \max _{x, y \geq 0} \Pi(x, y)$. However, if the constraint in (11) binds before manufacturer $Y$ 's surplus is fully extracted, then manufacturer $Y$ 's payoff satisfies

$$
\begin{aligned}
\pi_{Y} & =\lambda_{Y}\left(R\left(x^{* *}, y^{* *}\right)-T_{X}\left(x^{* *}\right)-c_{Y}\left(y^{* *}\right)-\left(R_{X}\left(x^{*}\right)-T_{X}\left(x^{*}\right)\right)\right) \\
& =\lambda_{Y}\left(\max _{y \geq 0} R\left(x^{*}, y\right)-c_{Y}(y)-R_{X}\left(x^{*}\right)\right)
\end{aligned}
$$

where the first line comes from (6), and the second line is obtained under the assumption that the constraint in (11) binds. In this case, the joint payoff of the retailer and manufacturer $X$ is

$$
\Pi\left(x^{* *}, y^{* *}\right)-\lambda_{Y}\left(\max _{y \geq 0} R\left(x^{*}, y\right)-c_{Y}(y)-R_{X}\left(x^{*}\right)\right),
$$


which is maximized by choosing $T_{X}$ such that

$$
\left(x^{* *}, y^{* *}\right) \in \arg \max _{x, y \geq 0} \Pi(x, y)
$$

and

$$
x^{*} \in \arg \min _{x \geq 0} \lambda_{Y}\left(\max _{y \geq 0} R(x, y)-c_{Y}(y)-R_{X}(x)\right) .
$$

It follows that overall joint payoff will be maximized whether or not (11) binds, and that manufacturer $Y$ 's payoff will be zero or $\lambda_{Y} \min _{x \geq 0} \max _{y \geq 0}\left(R(x, y)-c_{Y}(y)-R_{X}(x)\right)$, whichever is larger.

Proposition 1 For any $T_{X}(\cdot)$ that solves the program in (8)-(10), payoffs are given by

$$
\begin{aligned}
\tilde{\pi}_{b} & =\Pi_{X Y}-\tilde{\pi}_{X}-\tilde{\pi}_{Y} \\
\tilde{\pi}_{X} & =\lambda_{X}\left(\Pi_{X Y}-\tilde{\pi}_{Y}-\left(1-\lambda_{Y}\right) \Pi_{Y}\right) \\
\tilde{\pi}_{Y} & =\max \left\{0, \lambda_{Y} \min _{x \geq 0} \max _{y \geq 0}\left(R(x, y)-c_{Y}(y)-R_{X}(x)\right)\right\},
\end{aligned}
$$

where $\tilde{\pi}_{b}, \tilde{\pi}_{X}$, and $\tilde{\pi}_{Y}$ are the payoffs of the retailer, manufacturer $X$, and manufacturer $Y$, respectively. The overall joint payoff is maximized at $\Pi_{X Y}$ conditional on the available shelf space.

Proposition 1 implies that the retailer will carry both products and sell the monopoly quantity of each product if shelf space is plentiful. And if shelf space is scarce, then the retailer will only carry the product that offers the higher monopoly profit, and it will sell the monopoly quantity of that product. Thus, if shelf space is scarce and $\Pi_{Y}>\Pi_{X}$, the retailer will sell the monopoly quantity of product $Y$. If $\Pi_{X}>\Pi_{Y}$, the retailer will sell the monopoly quantity of product $X$.

\section{Stage one — retailer's shelf-space decision}

We now consider the retailer's decision on how much shelf space to build. If it builds two slots, then overall joint payoff $\left(\Pi_{X Y}=\Pi_{X}+\Pi_{Y}\right)$ will be higher than if it builds just one slot, but as we shall see, it will lose the ability to use its contract with manufacturer $X$ to shift rents from manufacturer $Y$. In contrast, if it builds one slot, then overall joint payoff $\left(\Pi_{X Y}=\max \left\{\Pi_{X}, \Pi_{Y}\right\}\right)$ will be lower, but now it will gain the ability to use $T_{X}$ to shift rents from manufacturer $Y$. Thus, the retailer faces a tradeoff when making its decision. Using Proposition 1, the precise tradeoff can best be seen by substituting $\tilde{\pi}_{X}$ into $\tilde{\pi}_{b}$ and then simplifying, thereby rewriting the retailer's payoff as

$$
\tilde{\pi}_{b}=\left(1-\lambda_{X}\right) \Pi_{X Y}+\lambda_{X}\left(1-\lambda_{Y}\right) \Pi_{Y}-\left(1-\lambda_{X}\right) \tilde{\pi}_{Y}
$$

This is increasing in the overall joint payoff, $\Pi_{X Y}$, but decreasing in manufacturer $Y$ 's payoff, $\tilde{\pi}_{Y}$. 
Consider first the case in which the retailer builds two slots. In this case, since the retailer can profitably carry and sell both products, its maximized revenue is given by $R(x, y)=R_{X}(x)+R_{Y}(y)$, and thus, from Proposition 1, manufacturer $Y$ 's payoff is

$$
\tilde{\pi}_{Y}=\max \left\{0, \lambda_{Y} \min _{x \geq 0} \max _{y \geq 0}\left(R_{Y}(y)-c_{Y}(y)\right)\right\}=\lambda_{Y} \Pi_{Y} .
$$

Substituting this into the retailer's payoff in (12) and simplifying yields

$$
\tilde{\pi}_{b}=\left(1-\lambda_{X}\right) \Pi_{X}+\left(1-\lambda_{Y}\right) \Pi_{Y}
$$

Notice that when shelf space is plentiful, contract $T_{X}$ has no effect on the negotiations between the retailer and manufacturer $Y$ (nor would contract $T_{Y}$ affect negotiations between the retailer and manufacturer $X$ if manufacturer $Y$ negotiated first). This follows because, as noted previously, $x^{* *}=x^{*}$ when shelf space is plentiful (and the products are independent), and similarly $y^{* *}=y^{*}$.

\section{The case of scarce shelf space}

In contrast, if shelf space is scarce, then the retailer cannot profitably carry and sell both products, and thus it follows from Proposition 1 that manufacturer $Y$ 's payoff is

$$
\begin{aligned}
\tilde{\pi}_{Y} & =\max \left\{0, \lambda_{Y} \min _{x \geq 0} \max _{y \geq 0}\left(\max \left\{R_{X}(x), R_{Y}(y)\right\}-c_{Y}(y)-R_{X}(x)\right)\right\} \\
& =\max \left\{0, \lambda_{Y}\left(\Pi_{Y}-\max _{x \geq 0} R_{X}(x)\right)\right\} .
\end{aligned}
$$

There is a big difference in this case from when shelf space is plentiful. Notice that manufacturer $Y$ 's payoff is strictly less when shelf space is scarce than when it is plentiful. In the latter case, manufacturer $Y$ 's product is always sold. However, when shelf space is scarce, manufacturer $Y$ 's product may or may not be sold depending on the relation between $\Pi_{X}$ and $\Pi_{Y}$. If it is sold, then whether manufacturer $Y$ earns positive surplus depends on the relation between $\max _{x \geq 0} R_{X}(x)$ and $\Pi_{Y}$. This is because the retailer earns up to $\max _{x \geq 0} R_{X}(x)$ in the out of equilibrium event it sells manufacturer $X$ 's product, and this limits the retailer's gains from trade with manufacturer $Y$.

If manufacturer $Y$ 's payoff is zero, which is the case if the monopoly value of manufacturer $X$ 's product is higher, or if $\max _{x \geq 0} R_{X}(x)>\Pi_{Y}>\Pi_{X}$, then the retailer's payoff in (12) simplifies to

$$
\tilde{\pi}_{b}=\left(1-\lambda_{X}\right) \Pi_{X Y}+\lambda_{X}\left(1-\lambda_{Y}\right) \Pi_{Y}
$$

If instead manufacturer $Y$ 's surplus is not fully extracted (which can only happen if $\Pi_{Y}>\max _{x \geq 0} R_{X}(x)>$ $\left.\Pi_{X}\right)$, then the retailer's payoff in (12) simplifies to

$$
\tilde{\pi}_{b}=\left(1-\lambda_{Y}\right) \Pi_{Y}+\lambda_{Y}\left(1-\lambda_{X}\right) \max _{x \geq 0} R_{X}(x) .
$$


Since $\tilde{\pi}_{b}$ is decreasing in $\tilde{\pi}_{y}$, it follows that the retailer's payoff in (15) is less than its payoff in (14).

\section{Comparing payoffs}

Comparing the retailer's payoff in (14) with its payoff in (13) yields an immediate result. If $\Pi_{X} \geq$ $\Pi_{Y}$, so that $\Pi_{X Y}=\Pi_{X}$ when shelf space is scarce, then the retailer's payoff is weakly higher in (13), i.e., when shelf space is plentiful (it is strictly higher in this case if $\lambda_{X}<1$ ). It follows that the retailer will not want to limit its shelf space if it negotiates first with the manufacturer whose monopoly payoff is higher. The decrease in overall joint payoff in this case always exceeds what the retailer could gain by extracting greater surplus from the manufacturer that negotiates second. ${ }^{14}$

More generally, comparing the retailer's payoff in (14) with its payoff in (13), it follows that the retailer earns higher payoff in (14), i.e., when shelf space is scarce, if and only if $\lambda_{X}<1$ and $\lambda_{Y} \Pi_{Y}>\Pi_{X}$. The analogous condition for when the retailer's payoff in (15) exceeds its payoff in (13) is $\lambda_{X}<1$ and $\lambda_{Y} \max _{x \geq 0} R_{X}(x)>\Pi_{X}$. This is summarized in the following proposition.

Proposition 2 There exist equilibria in which the retailer chooses to have scarce shelf space when slotting allowances are prohibited if and only if $\lambda_{Y} \min \left\{\max _{x \geq 0} R_{X}(x), \Pi_{Y}\right\} \geq \Pi_{X}$. If this inequality is strict and $\lambda_{X}<1$, then the retailer will choose to have scarce shelf space in all equilibria.

Proposition 2 implies that the retailer can sometimes earn higher payoff by limiting its shelf space, thereby destroying overall surplus. In other words, the vertically integrated outcome may not always be implemented even in this simple vertical chain with one retailer and two manufacturers. This result differs from that in the previous literature on common agency, such as Bernheim and Whinston (1985). Our main difference from this previous literature is that here the retailer has an additional strategic variable: its shelf space. As it turns out, for some environments, even though the retailer does not distort its price under common agency, it may distort its availability of shelf space (see also the result in O'Brien and Shaffer, 1997, for the case of simultaneous contracting).

The tradeoff for the retailer is whether to build one slot in order to capture a larger share of a smaller overall profit, or two slots in order to capture a smaller share of a larger overall profit. Since the difference in overall profit is $\Pi_{X}$, it follows that the larger is $\Pi_{X}$, (the right-hand side of

\footnotetext{
${ }^{14}$ This raises the question as to why the retailer would want to negotiate with manufacturer $X$ first if $X$ 's product is better than $Y$ 's product, when it could earn higher payoff by reversing the order. If the retailer could choose with whom to negotiate first, then clearly in the case of independent products and scarce shelf space, the retailer would prefer to negotiate first with the manufacturer whose product has the smaller monopoly payoff, as this benefits it more in extracting surplus from the stronger manufacturer. For an analysis of the retailer's optimal order of negotiations in a more general rent-shifting setting where products can be substitutes or complements, see Marx and Shaffer (2007).
} 
the condition in Proposition 2), the less likely it is that the retailer will opt to build one slot, all else equal. For a given $\Pi_{X}$, the larger is $\lambda_{Y}$, the smaller is the retailer's share of the profit when shelf space is plentiful. Although the retailer's profit share is also decreasing in $\lambda_{Y}$ when shelf space is scarce, the decrease is not as large given the possibilities for rent shifting. Thus, a larger value of $\lambda_{Y}$ makes it more likely that the retailer will opt to build only one slot, all else being equal.

\section{Slotting allowances and scarce shelf space}

It is sometimes alleged that the scarcity of shelf space found in practice is a disequilibrium phenomenon that will be self-correcting in the long run. Proposition 2 implies otherwise. It says that a shortage of shelf space can emerge in equilibrium as a consequence of profit-maximizing behavior by a retailer with market power. It follows that as long as there exist barriers to entry that protect long-run profits, shelf-space shortages need not be self-correcting. However, it may be possible to improve things at the margin through appropriate public policy. One practice that has received scrutiny, but for which the prevailing legal climate is permissive, is slotting allowances.

\section{The role of slotting allowances in the retailer's shelf-space decision}

The question we now ask is what impact will slotting allowances have on the scarcity of shelf space. Will they help to alleviate it, or will they contribute to it? We model slotting allowances as follows. After observing whether shelf space is plentiful or scarce, manufacturers have the opportunity to purchase slots for their products by offering slotting allowances. Consider first the case where shelf space is plentiful. In this case, the retailer has two slots available for purchase. However, since the manufacturers' products are independent, and each manufacturer needs at most one slot to satisfy the demand for its product, neither manufacturer has anything to gain from buying more than one slot. This means that a manufacturer can always count on a slot being available for its product, and thus, it follows that slotting allowances will not arise in equilibrium if shelf space is plentiful.

Now suppose that the retailer's shelf space is scarce. In this case, the retailer has only one available slot for purchase, and thus one product will necessarily be excluded. As a result, the retailer may demand that manufacturers offer slotting allowances, and the manufacturers may have no other alternative but to compete for the retailer's patronage by offering to pay for their shelf space. Let $S_{X} \geq 0$ denote manufacturer $X$ 's offer, and $S_{Y} \geq 0$ denote manufacturer $Y$ 's offer. One

can think of $S_{X}$ and $S_{Y}$ as lump-sum payments that are offered to the retailer in exchange for 
shelf space of fixed width (a slot) and duration (the rest of the game). Since the retailer has only one slot available for purchase when shelf space is scarce, it can accept at most one manufacturer's offer, where acceptance implies that the retailer's slot is reserved for that manufacturer's product.

If no offer is accepted, the slot remains under the retailer's control, no lump-sum payment is made, and the rest of the game proceeds as above. If the retailer accepts an offer, the manufacturer whose offer was accepted pays the retailer and then chooses along with the retailer the remaining contract terms to maximize their joint payoff, with each receiving its bargaining share of the incremental gains from trade. It follows that if the retailer accepts manufacturer $X$ 's offer, then the retailer's payoff is $\left(1-\lambda_{X}\right) \Pi_{X}+S_{X}$, manufacturer $X$ 's payoff is $\lambda_{X} \Pi_{X}-S_{X}$, and manufacturer $Y$ 's payoff is zero. ${ }^{15}$ If the retailer accepts manufacturer $Y$ 's offer, then the retailer's payoff is $\left(1-\lambda_{Y}\right) \Pi_{Y}+S_{Y}$, manufacturer $Y$ 's payoff is $\lambda_{Y} \Pi_{Y}-S_{Y}$, and manufacturer $X$ 's payoff is zero.

\section{Whose offer will be accepted?}

Solving the game with slotting allowances is straightforward. If the retailer were to accept manufacturer $X$ 's offer, then the joint payoff of the retailer and manufacturer $Y$ would be at most $\Pi_{X}$ (manufacturer $X$ cannot earn negative profit in equilibrium), which is less than what the joint payoff of the retailer and manufacturer $Y$ would be if the retailer were to accept manufacturer $Y$ 's offer (recall that $\Pi_{Y}>\Pi_{X}$ is necessary for scarce shelf space to arise in equilibrium). This implies that there is no equilibrium in which manufacturer $X$ outbids manufacturer $Y$ for shelf space. ${ }^{16}$

Similarly, if the retailer were to reject both offers, then the joint payoff of the retailer and manufacturer $Y$ would, from Proposition 1 , be $\Pi_{Y}-\lambda_{X} \lambda_{Y} \min \left\{\Pi_{Y}, \max _{x \geq 0} R_{X}(x)\right\}$, which is weakly less than what the joint payoff of the retailer and manufacturer $Y$ would be if the retailer were to accept manufacturer $Y$ 's offer (strictly less if $\lambda_{X}, \lambda_{Y}>0$ ). This implies that if $\lambda_{X}>0$ and $\lambda_{Y}>0$, there is no equilibrium in which shelf space is scarce and the retailer rejects both offers.

It follows that in any equilibrium with scarce shelf space, the retailer will accept manufacturer $Y$ 's offer and earn at least as much profit as it could earn if instead it accepted manufacturer $X$ 's offer or rejected both offers. It must also be the case that manufacturer $X$ cannot profitably deviate in equilibrium and that manufacturer $Y$ will offer no more than is necessary to obtain the retailer's

\footnotetext{
${ }^{15}$ We are implicitly assuming that if the retailer accepts manufacturer $X$ 's offer, then it is obligated to carry and sell product $X$. Alternatively, one might imagine that manufacturer $X$ could buy the shelf space slot but then allow the retailer to carry and sell product $Y$ instead. We can show that our results are robust to this possibility.

${ }^{16}$ Formally, there exists a payment $S_{Y}$ such that $\left(1-\lambda_{Y}\right) \Pi_{Y}+S_{Y}>\Pi_{X}$ and $\lambda_{Y} \Pi_{Y}-S_{Y}>0$. By offering an $S_{Y}$ that satisfies these inequalities, manufacturer $Y$ can induce the retailer to accept its offer and make itself better off.
} 
acceptance. Therefore, in any equilibrium with scarce shelf space, the retailer's payoff is given by

$$
\tilde{\pi}_{b}= \begin{cases}\max \left\{\Pi_{X},\left(1-\lambda_{X}\right) \Pi_{Y}+\lambda_{X}\left(1-\lambda_{Y}\right) \Pi_{Y}\right\}, & \text { if } \max _{x \geq 0} R_{X}(x) \geq \Pi_{Y} \\ \max \left\{\Pi_{X},\left(1-\lambda_{Y}\right) \Pi_{Y}+\lambda_{Y}\left(1-\lambda_{X}\right) \max _{x \geq 0} R_{X}(x)\right\}, & \text { if } \max _{x \geq 0} R_{X}(x)<\Pi_{Y} .\end{cases}
$$

The interpretation of (16) is straightforward. In any equilibrium with scarce shelf space, the retailer can earn $\Pi_{X}$ if it accepts manufacturer $X$ 's offer, and it can earn either the payoff in (14) or the payoff in (15) if it rejects both offers (where its payoff depends on whether manufacturer $Y$ would earn positive surplus - which depends on the relationship between $\max _{x \geq 0} R_{X}(x)$ and $\left.\Pi_{Y}\right)$. It follows that (16) represents the retailer's opportunity cost of accepting manufacturer $Y$ 's offer.

Comparing the retailer's payoff in (16) with its payoffs in (14) and (15), we see immediately that, conditional on shelf space being scarce, the retailer is weakly (sometimes strictly) better off when slotting allowances are feasible than when they are not. Intuitively, the retailer cannot be worse off with slotting allowances because it can always reject both offers and guarantee itself the minimum of the payoffs in (14) and (15). And it can sometimes be better off (e.g., when $\lambda_{X}, \lambda_{Y}=1$ ) because the auctioning of scarce shelf space forces the weaker manufacturer to compete away its entire surplus even if this manufacturer would otherwise have been able to earn positive payoff.

It follows that since the retailer can always choose whether to restrict its shelf space, the feasibility of slotting allowances cannot make the retailer worse off. Comparing the retailer's payoff in (16) with its payoff in (13), it also follows that the feasibility of slotting allowances may contribute to the scarcity of shelf space. Since the retailer earns at least $\Pi_{X}$ when shelf space is scarce and slotting allowances are permitted, a sufficient condition for the retailer to prefer to have one slot is

$$
\Pi_{X}>\left(1-\lambda_{X}\right) \Pi_{X}+\left(1-\lambda_{Y}\right) \Pi_{Y}
$$

which holds if and only if $\lambda_{X} \Pi_{X}>\left(1-\lambda_{Y}\right) \Pi_{Y}$. Combining this condition with the if and only if condition from Proposition $2, \lambda_{Y} \min \left\{\max _{x \geq 0} R_{X}(x), \Pi_{Y}\right\} \geq \Pi_{X}$, yields the following result.

Proposition 3 There exist equilibria in which the retailer chooses to have scarce shelf space when slotting allowances are permitted if and only if $\lambda_{Y} \min \left\{\max _{x \geq 0} R_{X}(x), \Pi_{Y}\right\} \geq \Pi_{X}$ or $\lambda_{X} \Pi_{X} \geq$ $\left(1-\lambda_{Y}\right) \Pi_{Y}$. If $\lambda_{X}<1$ and either inequality is strict, then scarce shelf space arises in all equilibria.

Conventional wisdom suggests that slotting allowances arise in response to scarce shelf space. In this view, the scarcity of shelf space is assumed to be exogenous. Here, we have shown that slotting allowances do not arise when shelf space is plentiful, and in that sense scarce shelf space 
causes slotting allowances. However, Proposition 3 implies that the causality can also go the other way - the scarcity of shelf space may, in part, be caused by the feasibility of slotting allowances.

We can illustrate the differences between Proposition 2 (where slotting allowances are not feasible) and Proposition 3 (where slotting allowances are feasible) in Figure 1 below. Assume $\lambda_{X}=\lambda_{Y}$ and $\max _{x \geq 0} R_{X}(x)>\Pi_{Y}$. Then Proposition 2 implies that shelf space will be scarce if and only if $\lambda_{Y} \Pi_{Y} \geq \Pi_{X}$ (region A), whereas Proposition 3 implies that shelf space will be scarce if and only if $\lambda_{Y} \Pi_{Y} \geq \Pi_{X}$ or $\lambda_{Y} \Pi_{X} \geq\left(1-\lambda_{Y}\right) \Pi_{Y}$ (regions $\mathrm{A}$ and $\mathrm{B}$ ). When slotting allowances are feasible, scarce shelf space arises when parameter values are in region A or B. When slotting allowances are not feasible, scarce shelf space arises only when parameter values are in region A.

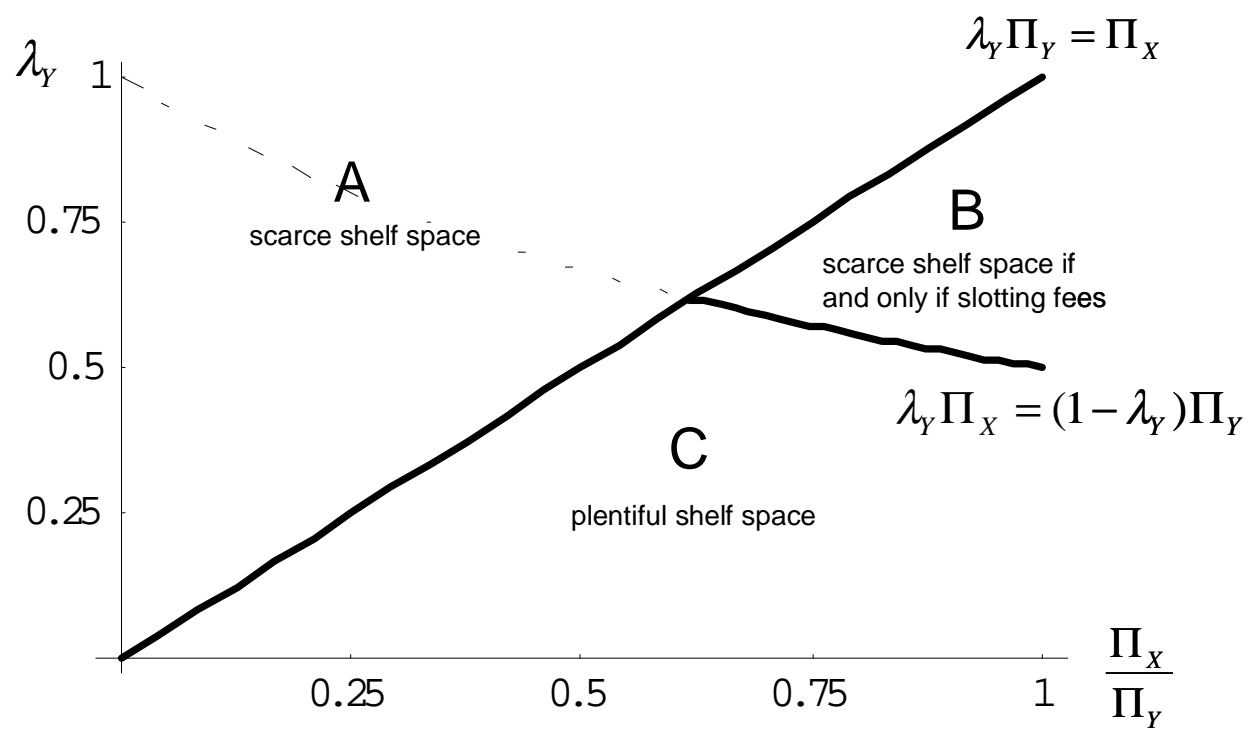

Figure 1: Shelf space with and without slotting allowances. The figure assumes $\lambda_{X}=\lambda_{Y}$ and $\max _{x \geq 0} R_{X}(x)>\Pi_{Y}$.

Slotting allowances contribute to the scarcity of shelf space in some environments (region B in Figure 1) because they provide the retailer with an additional means of shifting rent when shelf space is scarce. By auctioning off its shelf space upfront, the retailer can induce the winning manufacturer to give it a payoff that is at least equal to the payoff it could earn if it gave the space to the loser. This guarantees for the retailer a payoff equal to the smaller of the monopoly profits of the two manufacturers' products (in equilibrium, the manufacturer of the weaker product offers to sell its product at cost and earns zero profit). Note that without slotting allowances, the retailer has no such guarantee. Whether shelf space is plentiful or scarce, the retailer's payoff in the absence of slotting allowances is decreasing in the manufacturers' bargaining powers and is zero 
in the polar case in which both manufacturers can make take-it-or-leave-it offers. In contrast, the retailer always earns positive payoff with slotting allowances when shelf space is scarce. Thus, it follows that slotting allowances may contribute to the scarcity of shelf space and be particularly valuable to retailers that have local monopoly power but otherwise have little bargaining power.

\section{Bargaining power and slotting allowances}

The retailer's decision whether to limit its shelf space, and the extent to which the availability of slotting allowances contributes to this decision, depends on the retailer's bargaining power. Surprisingly, we see from Proposition 3 that there is an inverse relationship between the retailer's bargaining power with respect to each manufacturer and whether slotting allowances arise in equilibrium. ${ }^{17}$ Slotting allowances are less likely to arise in equilibrium when the retailer has more bargaining power (when $\lambda_{X}$ and $\lambda_{Y}$ are low) because with higher bargaining power the focus of the retailer shifts toward maximizing the overall profit rather than limiting its shelf space to extract rent. Slotting allowances do not arise, for example, if the retailer can make take-it-or-leave-it offers $\left(\lambda_{X}=\lambda_{Y}=0\right)$. This may explain why a retailer like Wal-Mart, which has high bargaining power vis-a-vis its suppliers, allegedly does not avail itself of these payments. We call this the 'Wal-Mart phenomenon.' The idea is that the usual tradeoff of whether to opt for a larger share of a smaller overall profit or a smaller share of a larger overall profit does not apply to Wal-Mart because it can already capture most or all of the profit. Hence, Wal-Mart prefers to have plentiful shelf space.

The Wal-Mart phenomenon is unusual in that Wal-Mart's bargaining power is thought to be high whether it is dealing with small manufacturers of produce or potentially large manufacturers of differentiated, consumer packaged goods. More generally, however, one can imagine that a retailer may have high bargaining power with respect to suppliers in some product classes, but low bargaining power with respect to suppliers in other product classes. If the retailer's shelf space decisions are localized (for example, products that require freezer space are competing only against themselves and not against products that do not need refrigeration), then it is possible that a given retailer may want strategically to limit its shelf space and obtain slotting allowances for some

\footnotetext{
${ }^{17}$ In our model, the retailer has some market power even if the manufacturers make take-it-or-leave-it offers, as the manufacturers have no alternative retailer to go to if they want to sell to the local consumers. For this reason, the retailer earns positive profit even when the manufacturers have all the bargaining power. Therefore, a more complete interpretation of our result is the following. First, suppose that the retailer does not have any market power, in that there are many potential retailers that each manufacturer can turn to. Clearly, under such a case, the retailer cannot benefit from limiting its shelf space (the manufacturers will go to another retailer), so slotting allowances will not arise in equilibrium. Second, as we have shown, slotting allowances do not arise if the retailer can make take-it-or-leave-it offers. These two polar cases suggest that for slotting allowances to arise, the retailer must have some market power (few alternative retailers), but not a significant bargaining power. We thank Yaron Yehezkel for this observation.
} 
product categories, but not limit its shelf space and thus not obtain slotting allowances for other product categories. In this case, our results imply that the incidence of slotting allowances will be higher in those product categories in which manufacturers have relatively more bargaining power.

Conditional on observing slotting allowances, one might think that a retailer with more bargaining power will obtain a larger slotting allowance than one that has less bargaining power. It turns out that this intuition holds in our model for some environments, but overall the relationship between a retailer's bargaining power and the size of the slotting allowance it obtains is non-monotonic. To see this, recall that the retailer's payoff when shelf space is scarce is given by ${ }^{18}$

$$
\left(1-\lambda_{Y}\right) \Pi_{Y}+S_{Y}=\max \left\{\Pi_{X}, \min \left\{\left(1-\lambda_{X} \lambda_{Y}\right) \Pi_{Y},\left(1-\lambda_{Y}\right) \Pi_{Y}+\lambda_{Y}\left(1-\lambda_{X}\right) \max _{x \geq 0} R_{X}(x)\right\}\right\}
$$

which implicitly defines $S_{Y}$. Subtracting $\left(1-\lambda_{Y}\right) \Pi_{Y}$ from both sides of this condition gives

$$
S_{Y}=\max \left\{\Pi_{X}-\left(1-\lambda_{Y}\right) \Pi_{Y},\left(1-\lambda_{X}\right) \lambda_{Y} \min \left\{\Pi_{Y}, \max _{x \geq 0} R_{X}(x)\right\}\right\},
$$

from which it follows that manufacturer $Y^{\prime}$ 's slotting offer, $S_{Y}$, is increasing in $\lambda_{Y}$ but weakly decreasing in $\lambda_{X}$ (strictly decreasing if the retailer's payoff exceeds $\Pi_{X}$ ). ${ }^{19}$ Intuitively, the larger is $\lambda_{X}$, the smaller is the retailer's disagreement payoff if it rejects both offers and thus the smaller is the slotting allowance that manufacturer $Y$ will offer in equilibrium. The larger is $\lambda_{Y}$, the less the retailer will earn in the continuation game if it accepts manufacturer $Y$ 's offer, and hence the more manufacturer $Y$ will have to offer upfront in the form of a slotting allowance.

As an example of how slotting allowances interact with the retailer's bargaining parameters, consider the case in which the retailer has equal bargaining power with respect to each manufacturer. Then, if the retailer's equilibrium payoff exceeds $\Pi_{X}$, slotting allowances will initially be increasing in the retailer's bargaining power and then decreasing, obtaining a maximum at $\lambda_{X}=\lambda_{Y}=1 / 2$.

\section{Slotting allowances, welfare, and profits}

Our results have implications for social welfare and the distribution of profits (who gains and who loses). Notice that if shelf space is plentiful, then the retailer sells both products and the overall joint payoff is $\Pi_{X}+\Pi_{Y}$. But if shelf space is scarce, then the retailer sells only product $Y$ and the overall joint payoff is $\Pi_{Y}$. In both cases, consumers face monopoly prices, which is true whether or

\footnotetext{
${ }^{18}$ The right-hand side of the equality in the displayed equation is just (16) written in a more compact way.

${ }^{19} \mathrm{It}$ is easily verified that $S_{Y}=0$ if and only if either $\lambda_{Y}=0$ or $\lambda_{X}=1$ and $\left(1-\lambda_{Y}\right) \Pi_{Y}>\Pi_{X}$. If $\lambda_{Y}=0$, then the retailer prefers to build two slots of shelf space. If $\lambda_{X}=1$ and $\left(1-\lambda_{Y}\right) \Pi_{Y}>\Pi_{X}$, then the retailer is indifferent between building one slot or two, as its payoff in both cases is $\left(1-\lambda_{Y}\right) \Pi_{Y}$. Thus, it follows that slotting allowances will be positive for all parameter values for which the retailer strictly prefers to limit its shelf space to one slot.
} 
not slotting allowances are feasible. Thus, conditional on the availability of shelf space, it follows that slotting allowances do not affect product selection or retail prices. However, as we have seen, the feasibility of slotting allowances do affect whether shelf space is scarce. In particular, we see from Propositions 2 and 3 that when slotting allowances are feasible, the retailer is more likely to limit its shelf space (see region B in Figure 1). When this happens (i.e., when parameter values are in this region), consumers are worse off with slotting allowances than without. Without slotting allowances, consumers would be able to select from among products $X$ and $Y$, each priced at the monopoly price. With slotting allowances, consumers would only be able to select product $Y$, and there would be no change in product $Y$ 's price. Since overall firm profits are also lower in region B with slotting allowances than without, it follows that welfare is unambiguously lower in this region.

Turning to the distribution of firm profits, the retailer is weakly better off with slotting allowances, and when $\Pi_{Y}>\Pi_{X}$, manufacturer $X$ is weakly worse off. Slotting allowances add to the retailer's profit when the monopoly profit of the losing manufacturer's product exceeds what the retailer could earn if it rejected both offers or built two slots of shelf space. Given $\Pi_{Y}>\Pi_{X}$, it follows that slotting allowances contribute to the retailer's profit if and only if $\Pi_{X}$ is larger than the retailer's payoff in (14) and (15), which for $\max _{x \geq 0} R_{X}(x) \geq \Pi_{Y}$, implies that $\Pi_{X}>\left(1-\lambda_{X} \lambda_{Y}\right) \Pi_{Y}$, and larger than its payoff when shelf space is plentiful, which implies that $\lambda_{X} \Pi_{X}>\left(1-\lambda_{Y}\right) \Pi_{Y}$.

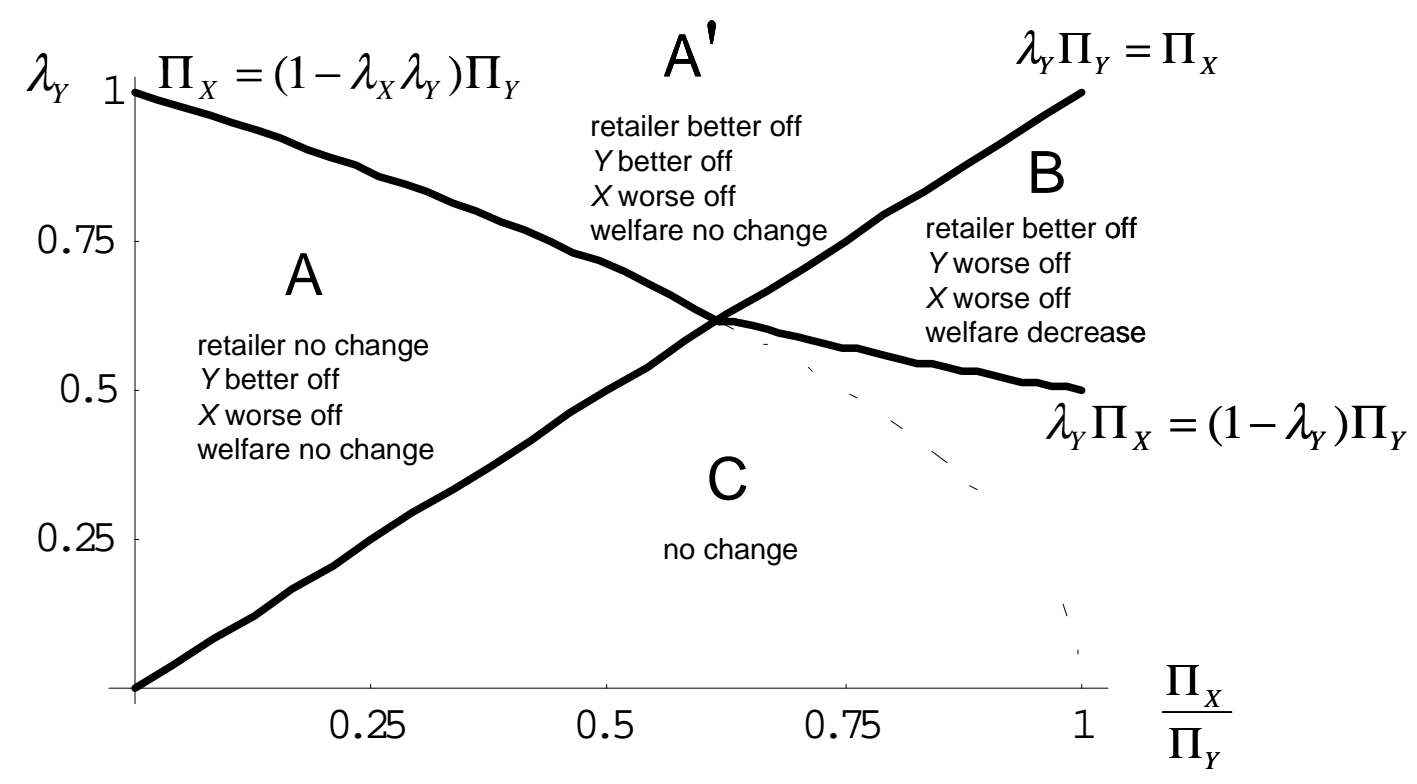

Figure 2: Slotting allowances and profits. The figure assumes $\lambda_{X}=\lambda_{Y}$ and $\max _{x \geq 0} R_{X}(x)>\Pi_{Y}$.

The upper envelope of these two inequalities is shown in Figure 2. For all points in regions $\mathrm{A}^{\prime}$ 
and $\mathrm{B}$, the retailer is better off with slotting allowances. For all points in regions $\mathrm{A}$ and $\mathrm{C}$, the retailer is indifferent to slotting allowances. Thus, for a given $\lambda_{Y}$, the retailer is more likely to gain from slotting allowances the larger is $\Pi_{X}$ relative to $\Pi_{Y}$ (the higher is the guaranteed payoff from slotting allowances). And, for a given ratio of $\Pi_{X}$ to $\Pi_{Y}$, the retailer is more likely to gain from slotting allowances the larger is $\lambda_{Y}$ (the higher is manufacturer $Y$ 's bargaining power). Since manufacturer $X$ 's profit decreases to zero when slotting allowances are feasible and shelf space is scarce, manufacturer $X$ is worse off in regions $\mathrm{A}, \mathrm{A}^{\prime}$, and $\mathrm{B}$. However, there is no change in its profit in region $\mathrm{C}$ because shelf space is plentiful in this case with or without slotting allowances.

Manufacturer $Y$ gains from slotting allowances in region A since manufacturer $X$ loses, the retailer's profit is unchanged, and overall joint payoff is unchanged. In region $\mathrm{A}^{\prime}$, the retailer picks up some of the profit lost by manufacturer $X$, but manufacturer $Y$ still gains because its payoff in this region, $\Pi_{Y}-\Pi_{X}$, exceeds its payoff in the absence of slotting allowances when shelf space is

scarce, $\max \left\{0, \lambda_{Y}\left(\Pi_{Y}-\max _{x \geq 0} R_{X}(x)\right)\right\}$. In region $\mathrm{B}$, manufacturer $Y$ earns $\Pi_{Y}-\Pi_{X}$ if slotting allowances are feasible and $\lambda_{Y} \Pi_{Y}$ otherwise. This implies that manufacturer $Y$ 's payoff is higher in region $\mathrm{B}$ with slotting allowances if and only if $\left(1-\lambda_{Y}\right) \Pi_{Y}>\Pi_{X}$. But for all points in the interior of region $\mathrm{B}, \lambda_{x} \Pi_{X}>\left(1-\lambda_{Y}\right) \Pi_{Y}$. Hence, manufacturer $Y$ loses in region B. However, there is no change in manufacturer $Y^{\prime}$ 's payoff in region $\mathrm{C}$ because shelf space is always plentiful in this case.

\section{Conclusion}

Slotting allowances have long been an issue in antitrust. They have been the subject of numerous congressional hearings and the focal point of two recent Federal Trade Commission reports on marketing practices in the retail grocery industry. Although some commentators view slotting allowances as anticompetitive, while others see them as procompetitive, many if not most commentators believe that the growth in slotting allowances can be attributed to the imbalance between the number of products (new products and established products) that are available for the retailer to choose from, and the number of products the retailer can adequately carry given its limited shelf space, i.e., given the scarcity of shelf space. In contrast, we show that causal linkages may also go the other way; slotting allowances may in fact be contributing to the scarcity of shelf space.

In our model, slotting allowances allow the retailer to capture more efficiently the value of its shelf space when shelf space is scarce. By itself, this effect is welfare neutral. Slotting allowances in this case serve only to transfer rents from the weaker manufacturer to the stronger manufacturer 
and, for some parameters, from the weaker manufacturer to the retailer. However, the problem is that this same mechanism may also induce the retailer to limit its shelf space when shelf space would otherwise be plentiful. This effect tends to reduce welfare and can harm both manufacturers. Welfare decreases when shelf space is scarce because consumers suffer from reduced product choice but do not benefit from lower prices. The manufacturers are worse off when shelf space would otherwise be plentiful because overall joint profit is lower, but the retailer's profit is higher.

Our results point to a new source of welfare loss. Policy makers have previously been concerned with whether slotting allowances would lead to higher or lower retail prices, and whether dominant manufacturers might abuse slotting allowances by buying up scarce shelf space in order to foreclose smaller rivals with better products. These concerns have caused policy makers in specific cases to consider whether the excluded firms have equal access to capital markets, whether slotting allowances are coupled with exclusivity provisions (e.g., whether the dominant firm requires that the downstream firm not sell its competitor's product), and whether there are scale economies in production that may prevent an excluded firm from effectively competing elsewhere in the marketplace. However, in our model, there is no effect on retail pricing, and the better product is always chosen conditional on the availability of shelf space. Instead, we find that welfare may be lower because slotting allowances may induce the retailer to limit its shelf space. This suggests that slotting allowances may be harmful even if they are not accompanied by exclusivity provisions, the market does not exhibit scale economies in production, and access to capital markets is not a concern.

Our results also have testable implications. In a recent study on slotting allowances, the Federal Trade Commission (2003, p.vi) concluded that, "For the five product categories during the time periods of this study, the surveyed retailers' data on the frequency of slotting fees varied widely between and within product categories, across retailers, and across a particular retailer's regions." The Federal Trade Commission (2003, p.vii) further concluded that, "For the seven retailers during the time periods of this study, slotting allowances were more prevalent for ice cream and salad dressing products than for bread and hot dog products." In some instances, the Federal Trade Commission found that slotting allowances were paid on all new products in a particular category. In other categories, they found that few if any slotting allowances were paid on the new products.

We suggest that these findings may be due to differences in the retailers' bargaining powers with respect to each manufacturer and with respect to each other. In particular, we have shown that the incidence of slotting allowances may be inversely related to each retailer's bargaining power. 
If a retailer with market power has all the bargaining power with respect to each manufacturer, then the retailer extracts all the available surplus in the market and slotting allowances do not arise. However, if the manufacturers have all the bargaining power, then slotting allowances will arise because the retailer will want to limit its shelf space in order to earn positive payoff. For intermediate levels of bargaining power, the retailer is more likely to limit its shelf space (and therefore slotting allowances are more likely to arise) the less bargaining power it has. This accords well with the observation that slotting allowances tend to arise for items such as ice cream and salad dressing, where strong brand names exist, but not for items where strong brand names do not exist, such as bread and hot dogs. This also accords well with the observation that Wal-Mart, a retailer that is thought to have a lot of bargaining power, allegedly does not accept slotting allowances.

We have also shown that, conditional on receiving slotting allowances, there is a non-monotonic relationship between a retailer's bargaining power and the magnitude of any slotting allowances it receives. Retailers with low bargaining power vis-a-vis their suppliers will tend to negotiate roughly the same level of slotting allowances as retailers with high bargaining power, whereas retailers with moderate bargaining power will be able to negotiate the highest slotting allowances. In principle, these findings can be tested, but, to our knowledge, the data needed to do so does not yet exist. 


\section{A Appendix}

Proof of Proposition 1. To complete the proof, it is sufficient to show that finding $T_{X}$ that solves the program in $(8)-(10)$ is equivalent to finding $\left(x_{2}, y_{2}, x_{1}, t_{2}, t_{1}\right)$ that solves the following program:

$$
\max _{x_{2} \geq 0, y_{2} \geq 0, x_{1} \geq 0, t_{2}, t_{1}} \Pi\left(x_{2}, y_{2}\right)-\tilde{\pi}_{Y}
$$

subject to

$$
\begin{gathered}
t_{2} \geq c_{X}\left(x_{2}\right), \\
\tilde{\pi}_{Y}=\lambda_{Y}\left(R\left(x_{2}, y_{2}\right)-t_{2}-c_{Y}\left(y_{2}\right)-\left(R\left(x_{1}, 0\right)-t_{1}\right)\right), \\
t_{2}-c_{X}\left(x_{2}\right)=\lambda_{X}\left(\Pi\left(x_{2}, y_{2}\right)-\tilde{\pi}_{Y}-\left(1-\lambda_{Y}\right) \Pi_{Y}\right), \\
y_{2} \in \arg \max _{y \geq 0} R\left(x_{2}, y\right)-c_{Y}(y), \\
R\left(x_{1}, 0\right)-t_{1} \geq R\left(x_{2}, 0\right)-t_{2}, \\
R\left(x_{2}, y_{2}\right)-t_{2}-c_{Y}\left(y_{2}\right) \geq \max _{y \geq 0} R\left(x_{1}, y\right)-t_{1}-c_{Y}(y) .
\end{gathered}
$$

Condition (A2) implies that manufacturer $Y$ earns non-negative profit. Conditions (A3) and (A4) imply that manufacturer $X$ and manufacturer $Y$, respectively, earn their bargaining share of the retailer's gains from trade with them. Condition (A5) implies that $y^{* *}$ maximizes the retailer's joint payoff with manufacturer $Y$. Condition (A6) implies that the retailer chooses $\left(x^{*}, 0\right)$ over $\left(x^{* *}, 0\right)$ when it only has a contract with manufacturer $X$. Condition (A7) implies that the retailer chooses $\left(x^{* *}, y^{* *}\right)$ over $\left(x^{*}, y\right)$ for any $y \geq 0$ when it has contracts in place with both manufacturers.

Suppose that $\hat{T}_{X}$ solves (8)-(10). Then we claim that

$$
\left(x_{2}, y_{2}, x_{1}, t_{2}, t_{1}\right) \equiv\left(x^{* *}\left(\hat{T}_{X}\right), y^{* *}\left(\hat{T}_{X}\right), x^{*}\left(\hat{T}_{X}\right), \hat{T}_{X}\left(x^{* *}\right), \hat{T}_{X}\left(x^{*}\right)\right)
$$

solves the program in (A1)-(A7). To see this, note that (6) implies (A3), (9) implies (A5), and (10) implies (A4). The definitions of $x^{* *}$ and $x^{*}$ imply that (A2), (A6), and (A7) are satisfied. Thus, $\left(x_{2}, y_{2}, x_{1}, t_{2}, t_{1}\right)$ is a feasible solution to (A1)-(A7). Suppose $\left(x_{2}, y_{2}, x_{1}, t_{2}, t_{1}\right)$ does not solve this

program. Then there exists $\left(x_{2}^{\prime}, y_{2}^{\prime}, x_{1}^{\prime}, t_{2}^{\prime}, t_{1}^{\prime}\right)$ satisfying (A2)-(A7) such that the maximand in (A1) is greater at $\left(x_{2}^{\prime}, y_{2}^{\prime}, x_{1}^{\prime}, t_{2}^{\prime}, t_{1}^{\prime}\right)$ than at $\left(x_{2}, y_{2}, x_{1}, t_{2}, t_{1}\right)$. Consider contract $T_{X}^{\prime}$ defined by:

$$
T_{X}^{\prime}(x) \equiv \begin{cases}t_{2}^{\prime}, & \text { if } x=x_{2}^{\prime} \\ t_{1}^{\prime}, & \text { if } x=x_{1}^{\prime} \\ \infty, & \text { otherwise }\end{cases}
$$


Because $\left(x_{2}^{\prime}, y_{2}^{\prime}, x_{1}^{\prime}, t_{2}^{\prime}, t_{1}^{\prime}\right)$ satisfies $(\mathrm{A} 2)-(\mathrm{A} 7)$ it follows that $\left(x^{* *}\left(T_{X}^{\prime}\right), y^{* *}\left(T_{X}^{\prime}\right)\right)=\left(x_{2}^{\prime}, y_{2}^{\prime}\right)$ and $x^{*}\left(T_{X}^{\prime}\right)=x_{1}^{\prime}$, and so $T_{X}^{\prime}$ satisfies (9)-(10). Thus, $T_{X}^{\prime}$ is a feasible solution to (8)-(10) and gives the retailer and manufacturer $X$ higher joint payoff than $\hat{T}_{X}$, a contradiction. Thus, $\left(x_{2}, y_{2}, x_{1}, t_{2}, t_{1}\right) \equiv$ $\left(x^{* *}\left(\hat{T}_{X}\right), y^{* *}\left(\hat{T}_{X}\right), x^{*}\left(\hat{T}_{X}\right), \hat{T}_{X}\left(x^{* *}\right), \hat{T}_{X}\left(x^{*}\right)\right)$ solves $(\mathrm{A} 1)-(\mathrm{A} 7)$.

Now suppose $\hat{T}_{X}$ is not an equilibrium contract. Then $\hat{T}_{X}$ does not solve (8)-(10). Because $\hat{T}_{X}$ is not an equilibrium contract, the contract $T_{X}^{\prime \prime}$, where

$$
T_{X}^{\prime \prime}(x) \equiv \begin{cases}\hat{T}_{X}\left(x^{* *}\left(\hat{T}_{X}\right)\right), & \text { if } x=x^{* *}\left(\hat{T}_{X}\right) \\ \hat{T}_{X}\left(x^{*}\left(\hat{T}_{X}\right)\right), & \text { if } x=x^{*}\left(\hat{T}_{X}\right) \\ \infty, & \text { otherwise }\end{cases}
$$

is also not an equilibrium contract. If $T_{X}^{\prime \prime}$ is not a feasible solution to (8)-(10), then at least one of $(9)-(10)$ is violated. Consider $\left(x_{2}, y_{2}, x_{1}, t_{2}, t_{1}\right) \equiv\left(x^{* *}\left(\hat{T}_{X}\right), y^{* *}\left(\hat{T}_{X}\right), x^{*}\left(\hat{T}_{X}\right), \hat{T}_{X}\left(x^{* *}\right), \hat{T}_{X}\left(x^{*}\right)\right)$. If $T_{X}^{\prime \prime}$ violates $(9)$, then $\left(x_{2}, y_{2}, x_{1}, t_{2}, t_{1}\right)$ violates at least one of $(\mathrm{A} 2)-(\mathrm{A} 7)$. If $T_{X}^{\prime \prime}$ violates $(10)$, then $\left(x_{2}, y_{2}, x_{1}, t_{2}, t_{1}\right)$ violates $(\mathrm{A} 4)$. If $T_{X}^{\prime \prime}$ is a feasible solution to (8)-(10), then there exists $T_{X}^{\prime \prime \prime}$ also feasible but giving a higher value of the maximand in (8). Then $\left(x_{2}, y_{2}, x_{1}, t_{2}, t_{1}\right)$ and

$$
\left(x_{2}^{\prime \prime \prime}, y_{2}^{\prime \prime \prime}, x_{1}^{\prime \prime \prime}, t_{2}^{\prime \prime \prime}, t_{1}^{\prime \prime \prime}\right) \equiv\left(x^{* *}\left(T_{X}^{\prime \prime \prime}\right), y^{* *}\left(T_{X}^{\prime \prime \prime}\right), x^{*}\left(T_{X}^{\prime \prime \prime}\right), T_{X}^{\prime \prime \prime}\left(x^{* *}\right), T_{X}^{\prime \prime \prime}\left(x^{*}\right)\right)
$$

both satisfy (A2)-(A7), but $\left(x_{2}^{\prime \prime \prime}, y_{2}^{\prime \prime \prime}, x_{1}^{\prime \prime \prime}, t_{2}^{\prime \prime \prime}, t_{1}^{\prime \prime \prime}\right)$ results in a higher value of the maximand in (A1) than $\left(x_{2}, y_{2}, x_{1}, t_{2}, t_{1}\right)$. Thus, $\left(x^{* *}\left(\hat{T}_{X}\right), y^{* *}\left(\hat{T}_{X}\right), x^{*}\left(\hat{T}_{X}\right), \hat{T}_{X}\left(x^{* *}\right), \hat{T}_{X}\left(x^{*}\right)\right)$ does not solve (A1)(A7). Q.E.D. 


\section{References}

Aghion, P. and P. Bolton (1987), Contracts as a Barrier to Entry, American Economic Review 77: $388-401$.

Bernheim, B. D. and M. Whinston (1985), Common Marketing Agency as a Device for Facilitating Collusion, Rand Journal of Economics 15: 269-281.

Bloom, P., G. Gundlach, and J. Cannon (2000), Slotting Allowances and Fees: Schools of Thought and the Views of Practicing Managers, Journal of Marketing 64: 92-108.

Canadian Competition Bureau (2002), The Abuse of Dominance Provisions as Applied to the Canadian Grocery Sector, available at http://cb-bc.gc.ca/epic/internet/incb-bc.nsf/en/ct02465e.html.

Chu, W. (1992), Demand Signaling and Screening in Channels of Distribution, Marketing Science 11: $327-347$.

Dana, J. (2004), Buyer Groups as Strategic Commitments, Working Paper, Northwestern University.

Federal Trade Commission (2001), Report on the Federal Trade Commission Workshop on Slotting Allowances and Other Marketing Practices in the Grocery Industry, Washington: D.C., available at http://www.ftc.gov/opa/2001/02/slotting.htm.

Federal Trade Commission (2003), Slotting Allowances in the Retail Grocery Industry: Selected Case Studies in Five Product Categories, Washington: D.C., available at http://www.ftc.gov/opa/2003/11/slottingallowance.htm.

Foros, O. and H. Kind (2008), Do Slotting Allowances Harm Retail Competition?, Scandinavian Journal of Economics 110: 367-384.

Gundlach, G. and P. Bloom (1998), Slotting Allowances and the Retail Sale of Alcohol Beverages, Journal of Public Policy and Marketing 17: 173-184.

Inderst, I. and G. Shaffer (2007), Retail Mergers, Buyer Power, and Product Variety, Economic Journal 117: 45-67.

Innes, R. and R. J. Sexton (1994), Strategic Buyers and Exclusionary Contracts, American Economic Review 84: 566-84.

Israilevich, G. (2004), Assessing Supermarket Product-Line Decisions: The Impact of Slotting Fees, Quantitative Marketing and Economics 2: 141-167.

Kelly, K. (1991), The Antitrust Analysis of Grocery Slotting Allowances: The Procompetitive Case, Journal of Public Policy and Marketing 10: 187-198.

Kuksov, D. and A. Pazgal (2007), The Effects of Costs and Competition on Slotting Allowances, Marketing Science 26: 259-267.

Lariviere, M. and V. Padmanabhan (1997), Slotting Allowances and New Product Introductions, Marketing Science 16: 112-128. 
Marx, L. M. and G. Shaffer (2004), Rent Shifting, Exclusion, and Market-Share Discounts, Working Paper, Duke University.

Marx, L. M. and G. Shaffer (2007), Rent Shifting and the Order of Negotiations, International Journal of Industrial Organization 25: 1109-1125.

Marx, L. M. and G. Shaffer (2007), Upfront Payments and Exclusion in Downstream Markets, Rand Journal of Economics 38: 823-843.

O'Brien, D. P. and G. Shaffer (1997), Nonlinear Supply Contracts, Exclusive Dealing, and Equilibrium Market Foreclosure, Journal of Economics and Management Strategy 6: 755-785.

Rao, A. and H. Mahi (2003), The Price of Launching a New Product: Empirical Evidence on Factors Affecting the Relative Magnitudes of Slotting Allowances, Marketing Science 22: $246-268$.

Shaffer, G. (1991), Slotting Allowances and Resale Price Maintenance: A Comparison of Facilitating Practices, Rand Journal of Economics 22: 120-135.

Shaffer, G. (2005), Slotting Allowances and Optimal Product Variety, The B.E. Journal of Economic Analysis 85 Policy, Vol 5: Iss. 1 (Advances), Article 3, 2005. available at http://www.bepress.com/bejeap/ advances/vol5/iss1/art3.

Spier, K. and Whinston, M. D. (1995), On the Efficiency of Privately Stipulated Damages for Breach of Contract: Entry Barriers, Reliance, and Renegotiation, RAND Journal of Economics 26: 180-202.

Sullivan, M. (1997), Slotting Allowances and the Market for New Products, Journal of Law and Economics 40: 461-493. 